\title{
Photorefractive Keratectomy in Keratoconus
}

\author{
Deepali Sandeep Tambe Anders Ivarsen Jesper Hjortdal \\ Department of Ophthalmology, Aarhus University Hospital, Aarhus, Denmark
}

\section{Key Words}

Photorefractive keratectomy $\cdot$ Keratoconus $\cdot$ Refractive surgical procedures

\begin{abstract}
Purpose: To assess the efficacy and safety of topography-guided photorefractive keratectomy (PRK) for keratoconus and to estimate the subsequent risk of progression. Methods: This is a retrospective follow-up study. Between 1998 and 2013, 28 eyes of 23 patients (age 1760) with grade 1-3 keratoconus received topography-guided PRK. Corrected-distance visual acuity (CDVA), keratometry, pachymetry, and corneal topography were assessed before, after 3 months, and at a late follow-up of a median of 7 years after the procedure. Postoperative complications including subsequent keratoplasty were noted. Results: Of the 28 eyes, 5 (18\%) had undergone corneal transplantation at a median of 7 years (range 3-10) after PRK. Four eyes were not available for follow-up. In the remaining 19 eyes, CDVA was improved in 16 eyes (84.3\%), reduced in 2 eyes (10.5\%), and unchanged in 1 eye (5.2\%). Thus, average CDVA had improved from 0.49 logMAR before PRK to 0.27 logMAR at 3 months, and to 0.24 at the long-term follow-up. The mean spherical equivalent was reduced from -6.2 to $-3.7 \mathrm{dpt}$ after 3 months and to $-2.1 \mathrm{dpt}$ at the late follow-up. Similarly, the mean cylinder was reduced from -4.2 to $-3.0 \mathrm{dpt}$ after 3 months and at the late follow-up. Conclusion: Topographyguided PRK in keratoconus may be effective for reducing myopia and astigmatism and may offer a temporary or permanent alternative to keratoplasty in contact lens-intolerant keratoconus. In the present study, we found a low risk of keratoconus progression after PRK.
\end{abstract}


Tambe et al.: Photorefractive Keratectomy in Keratoconus

\section{Introduction}

Keratoconus is characterized by progressive corneal protrusion and thinning that leads to irregular astigmatism and impairment in visual function [1,2]. During the past two decades, new developments in visual rehabilitation of keratoconus have been introduced, including new contact lens designs, photorefractive keratectomy (PRK), collagen cross-linking, intrastromal corneal ring segments, phakic intraocular lenses, and penetrating or lamellar keratoplasty in advanced stages [2].

Current regimes for PRK utilize topography-guided ablation profiles, intended to reduce corneal surface irregularities and improve vision. Corneal thinning disorders weaken the mechanical strength of affected corneas, suggesting that photorefractive procedures may be contraindicated in keratoconus. Few cases have been reported to confirm this hypothesis [3]. Although corneal ectasia has been described after PRK in keratoconus suspect cases [4], other studies report encouraging results using PRK alone [5-7].

Between 1998 and 2013, we treated 28 eyes of 23 keratoconus patients with PRK. The main objective was to improve visual acuity with spectacles or contact lenses, delaying or avoiding more extensive surgical interventions such as keratoplasty.

The aim of the current study was to evaluate the long-term efficacy and safety of PRK for keratoconus and to assess the risk of progression of the disease after the excimer laser procedure. As there are very few reports on this subject, we believe our study to be of interest in spite of the retrospective design and relatively small sample size.

\section{Patients and Methods}

\section{Subjects}

A total of 28 eyes of 23 patients (16 male and 7 female; median age 36 years, range 1760) treated with topography-guided PRK between 1998 and 2013 were retrospectively identified from electronic patient records at the Department of Ophthalmology, Aarhus University Hospital, Denmark. All patients had originally been referred from a general ophthalmologist for corneal transplantation due to poor visual acuity with glasses and intolerance to contact lenses. The diagnosis of keratoconus was based on a combination of slit-lamp biomicroscopy, corneal topography, auto-keratometry, and corneal pachymetry. Preoperative and short-term postoperative data were collected from the patient's medical records. All patients had a preoperative keratoconus grade of 1-3 on the Amsler-Krumeich classification. Corneal haze was graded using the Fantes score. In 5 patients, both eyes had been treated. Two patients received one PRK retreatment, and 1 patient received two PRK retreatments. Patients were invited to a late follow-up examination in 2013-2014.

\section{Inclusion and Exclusion Criteria}

The total number of treated patients was 23 (28 eyes). When evaluating the electronic patient records, 5 patients ( 5 eyes) were found to have undergone keratoplasty at some time after PRK treatment. These 5 cases were classified as failed, and the patients were not invited to the follow-up visit. Two patients ( 2 eyes) could not be contacted because of change of address, and 1 patient ( 2 eyes) was not interested in participating in a long-term follow-up visit. Two patients ( 2 eyes) did not attend the 3-month follow-up. Thus, the statistical analyses included 26 eyes of 21 patients at the 3-month follow-up and 19 eyes of 16 patients at the long-term follow-up (fig. 1). The patient ( 2 eyes) who was not interested in a long-term 
Tambe et al.: Photorefractive Keratectomy in Keratoconus

follow-up visit reported to be satisfied with the treatment (telephone conversation). Therefore, satisfaction data include 21 eyes of 17 patients.

\section{Surgical Technique}

Orbscan II slit-scanning (Bausch and Lomb, Rochester, N.Y., USA) topography maps were used for topography-supported planning (TOSCA) of the ablation in patients treated from 1998 to 2005 (12 eyes). Patients treated between 2005 and 2013 (16 eyes) were measured with the ATLAS topographer (Carl Zeiss Meditec, Jena, Germany) and treatment planning was performed using the CRS Master software module. PRK was performed in topical anesthesia. All patients were treated by one of two surgeons (Dr. Jesper Hjortdal or Dr. Niels Ehlers, Aarhus University Hospital). A circular corneal marker was used to define an 8$\mathrm{mm}$ zone centered over the pupil. A surgical sponge was used for brief application of alcohol, followed by immediate wiping with a sponge wetted in physiological saline. Subsequently, the central epithelium was removed with a blunt Beaver knife. The excimer laser photoablation was performed with a MEL-70 (12 eyes, from 1998 to 2005) or a MEL-80 (16 eyes, from 2005 to 2013) flying spot excimer laser (Carl Zeiss Meditec). The optical zone ranged from 6.0 to $6.5 \mathrm{~mm}$ in diameter. The mean ablation depth was $82 \mu \mathrm{m}$ (SD 17.8, range 45-112). Topical mitomycin C $0.02 \%$ for $20 \mathrm{~s}$ was applied in 3 re-treated patients (5 eyes) to minimize postoperative haze. Following the excimer laser treatment, one drop of cyclopentolate 1\%, one drop of diclofenac $0.1 \%$, and chloramphenicol ointment were applied.

\section{Postoperative Treatment and Follow-Up}

The postoperative treatment consisted of chloramphenicol eye drops $0.5 \%$ and prednisolone eye drops $(0.5 \%) 4$ times a day for 2 weeks and then 2 times a day for 2 weeks. Patients were examined preoperatively and were offered visits at 1, 3, 6, 9, and 12 months after surgery. At all visits, patients received routine clinical examination with slit-lamp biomicroscopy, determination of corrected-distance visual acuity (CDVA), pachymetry, and corneal topography with TMS-1 or TMS-3 (Tomey, Nagoya, Japan), ATLAS (Carl Zeiss Meditec), or Pentacam HR (Oculus, Wetzlar, Germany). At the late follow-up visit at a median of 7 years (range 2-14) after the procedure, patients were asked about their satisfaction with the PRK procedure in each eye, simply stating whether they were satisfied or dissatisfied. Visual acuity data were converted from Snellen equivalent to logMAR. The main outcome parameters were considered to be change in CDVA, spherical equivalent (SE) refraction, refractive cylinder, changes in keratometry (Kmax; taken from the steepest keratometer reading), as well as overall failure (need for keratoplasty or planned additional surgery). Central corneal thicknesses (CCT) as well as development of corneal haze were considered to be secondary parameters. Keratoconus progression was defined as an increase in the steepest keratometry measures, with concurrent changes in subjective refraction, topography, and corneal thickness between 3 months after PRK and the late follow-up visit.

\section{Statistical Analysis}

Statistical analysis was performed using Graphpad PRISM version (6.0d) software. Preoperative, early postoperative (3-month follow-up), and late postoperative parameters were compared using paired $t$ tests. A $p$ value $<0.05$ was considered statistically significant. 
Tambe et al.: Photorefractive Keratectomy in Keratoconus

\section{Results}

Keratoconus Progression

Keratoconus showed no progression in 15 out of 19 eyes (79\%) at the late follow-up. Five of the total 28 eyes (18\%), however, had undergone corneal transplantation during the years after PRK, and 1 patient (3\%) was scheduled for implantation of intrastromal corneal ring segments (ICRS). The median age of transplanted patients at the time of PRK was 47 years (range 30-51). Three of the grafted patients had an initial effect of the topographyguided PRK treatment but had subsequent progression and developed pronounced keratoconus at a median of 7 years (range 3-10) after surgery. A fourth patient was transplanted due to development of central grade 2 haze after PRK, but keratoconus was stable. A fifth patient was transplanted because the expected results after PRK were not achieved.

\section{Subjective Satisfaction}

Long-term follow-up, a median of 7 years after PRK, showed that 13 patients (16 eyes) were satisfied and 4 patients ( 5 eyes) were dissatisfied with the PRK procedure. Thus, longterm satisfaction with the PRK procedure was obtained in at least 16 of the 28 eyes treated (57\%).

\section{Uncorrected-Distance Visual Acuity}

Mean preoperative uncorrected-distance visual acuity improved significantly from $20 / 250$ (1.1 logMAR) before surgery to 20/100 (0.7 logMAR) at the late follow-up visit ( $\mathrm{p}<$ $0.05)$.

\section{Corrected-Distance Visual Acuity}

In the 26 eyes attending the 3-month follow-up, CDVA had improved by 1-7 Snellen lines in 21 eyes (81\%) and was unchanged in the remaining 5 eyes (19\%). In the 19 eyes attending the long term follow-up, CDVA had improved by 1-4 Snellen lines in 16 eyes (84\%), was reduced by 1-2 Snellen lines in 2 eyes (11\%), and was unchanged in 1 eye (5\%) (table 1). The average CDVA improved significantly after topography-guided PRK, from $20 / 60$ (0.49 logMAR) before surgery to 20/40 (0.27 logMAR) after 3 months and at the late follow-up.

\section{Refractive Outcome}

Mean SE refraction was significantly reduced by $2.5 \mathrm{dpt}$ at 3 months $(\mathrm{p}<0.05)$ and by $4.1 \mathrm{dpt}$ at the long-term follow-up ( $\mathrm{p}<0.05$; table 2, fig. $2 \mathrm{~b}$ ). In a paired comparison, SE had not changed significantly from the 3-month follow-up to the long-term follow-up visit $(p>$ $0.05)$. The mean refractive astigmatism was significantly reduced with $1.2 \mathrm{dpt}$ at 3 months $(\mathrm{p}<0.05)$ as well as at the long-term follow-up $(\mathrm{p}<0.05$; table 2 , fig. $2 \mathrm{c})$.

\section{Change in Corneal Thickness}

Mean preoperative CCT was $484 \mu \mathrm{m}$ (SD 45 , range 410-610). CCT was significantly reduced to $440 \mu \mathrm{m}$ (SD 43, range 337-540) at the 3-month follow-up and to $434 \mu \mathrm{m}$ (SD 57, range 337-560) at the long-term follow-up ( $p<0.05$; fig. 3a).

\section{Changes in Keratometry}

Changes in keratometry (Kmax) were taken from the steepest keratometer reading. Mean preoperative Kmax was 50.6 dpt (SD 3.5, range 44.29-57.89), and mean postoperative Kmax was 48.92 dpt (SD 3.0, range 43.4-53.8) after 3 months, and 49.3 dpt (SD 3.3, range 
Tambe et al.: Photorefractive Keratectomy in Keratoconus

44.8-56.6) at the long-term follow-up. Thus, Kmax measurements were reduced by $1.7 \mathrm{dpt}$ by 3 months $(p<0.05)$ and $1.3 \mathrm{dpt}$ after a median of 7 years $(\mathrm{p}>0.05$; fig. $3 \mathrm{~b})$.

Corneal Haze

By 3 months, 20 eyes had developed haze grade 1-2 and 6 eyes had developed haze grade 3-4. At the long-term follow-up, 3 eyes had no haze, 15 eyes had haze grade 1, and 1 eye had haze grade 2 .

\section{Discussion}

The pathogenesis of keratoconus is not known in details, but Nielsen et al. [8] found that the protein expression is altered in the corneal epithelium with changes of the cytoskeleton, reduced extracellular matrix remodeling, altered transmembrane signaling, and modified cell-to-cell and cell-to-matrix interactions. Meek et al. [9] reported that the collagenous internal structure of the cornea is eventually altered after the PRK procedure, resulting in corneal thinning and ectasia. Cennamo et al. [6] reported a significant decrease in all keratoconus indices during 24 months of follow-up of 25 treated eyes versus an increase in indices in untreated control eyes, suggesting a possible therapeutic effect of an excimer laser treatment in keratoconus. Guedj et al. [7] treated 62 eyes of 42 patients with suspected keratoconus with PRK and found a significant improvement in visual acuity, which remained stable during a follow-up period of up to 5 years. Chelala et al. [10] also reported that in mild to moderate keratoconus PRK is a safe and effective procedure for improving uncorrected vision in patients with small refractive errors. In contrast, Kasparova and Kasparov [11] reported progression of keratoconus in $8.6 \%$ eyes in the first sixth months after surgery. Koller et al. [12] suggested corneal topography monitoring for up to 5 years to be sure that a PRK procedure does not induce keratoconus progression in corneas documented to be preoperatively stable for years. In fact, corneal ectasia can occur even a decade after PRK [13]. Furthermore, in comparison with PRK, ICRS has the advantage of being a reversible procedure in mild to moderate keratoconus. Still, the very long-term stability of the procedure remains unknown [14].

In the current case series, all eyes had manifest keratoconus and were treated without adjunctive therapies such as collagen cross-linking, which had not been introduced into clinical use at the time of treatment of most of these eyes. We evaluated topography-based PRK, which was intended to reduce myopia and astigmatism and improve uncorrected and bestcorrected visual acuity.

In the present study, keratoconus progression at a median of 7 years (range 3-10) after PRK is reported. Significant visual improvement was obtained in $84 \%$ of patients who were available for the late follow-up, and progression could not be observed in $79 \%$ of these patients. The overall risk of progression in our cohort was 6 out of 24 eyes (25\%). We also observed that 3 patients who showed keratoconus progression had a median age of around 47 at the time of PRK. It is very rare to see progression at this high age, so performing a PRK procedure, which leads to further thinning of the cornea, could be an initiating factor for progression of the disease in elderly patients.

As all of these 23 patients were initially referred for corneal transplantation, the study may indicate that 4 out of 5 patients with contact lens intolerance and mild or moderate keratoconus may avoid transplantation by performing a PRK procedure. In addition, at least 3 out of 5 patients were satisfied with the procedure at the long-term follow-up. 
Tambe et al.: Photorefractive Keratectomy in Keratoconus

In conclusion, although keratoconus is generally thought to be an absolute contraindication for PRK, our results indicate that topography-guided PRK may be a viable option for reducing myopia or astigmatism and improving visual acuity in selected keratoconus eyes. The present study found limited keratoconus progression after PRK.

\section{Acknowledgements}

The authors would like to thank Nicolaj Aagaard, Jens Christian Hedegaard, Henrik Sejersen, and Christina Møller for invaluable aid with the late clinical controls.

\section{Statement of Ethics}

The study complied with the Declaration of Helsinki, and all participants signed a written informed consent form before participation. The Central Denmark Region Committees on Health Research Ethics classified the study as a quality control study, which does not require formal ethics approval according to Danish law.

\section{Disclosure Statement}

The authors have no financial disclosures.

\section{References}

1 Vazirani J, Basu S: Keratoconus: current perspectives. Clin Ophthalmol 2013;7:2019-2030.

-2 Fadlallah A, Dirani A, EI Rami H, Cherfane G, Jarade E: Safety and visual outcome of Visian toric ICL implantation after corneal collagen cross-linking in keratoconus. J Refract Surg 2013;29:84-89.

3 Schmitt-Bernard CF, Lesage C, Arnaud B: Keratectasia induced by laser in situ keratomileusis in keratoconus. J Refract Surg 2000;16:368-370.

-4 Dawson DG, Randleman JB, Grossniklaus HE, et al: Corneal ectasia after excimer laser keratorefractive surgery: histopathology, ultrastructure, and pathophysiology. Ophthalmology 2008;115:2181-2191.

5 Bilgihan K, Ozdek SC, Konuk O, Akata F, Hasanreisoglu B: Results of photorefractive keratectomy in keratoconus suspects at 4 years. J Refract Surg 2000;16:438-443.

6 Cennamo G, Intravaja A, Boccuzzi D, Marotta G, Cennamo G: Treatment of keratoconus by topographyguided customized photorefractive keratectomy: two-year follow-up study. J Refract Surg 2008;24:145149.

-7 Guedj M, Saad A, Audureau E, Gatinel D: Photorefractive keratectomy in patients with suspected keratoconus: five-year follow-up. J Cataract Refract Surg 2013;39:66-73.

-8 Nielsen K, Birkenkamp-Demtröder K, Ehlers N, Orntoft TF: Identification of differentially expressed genes in keratoconus epithelium analyzed on microarrays. Invest Ophthalmol Vis Sci 2003;44:2466-2476.

-9 Meek KM, Tuft SJ, Huang Y, et al: Changes in collagen orientation and distribution in keratoconus corneas. Invest Ophthalmol Vis Sci 2005;46:1948-1956.

$\rightarrow 10$ Chelala E, Rami HE, Dirani A, Fadlallah A, Fakhoury O, Warrak E: Photorefractive keratectomy in patients with mild to moderate stable keratoconus: a five-year prospective follow-up study. Clin Ophthalmol 2013;7:1923-1928.

-11 Kasparova EA Kasparov AA: Six-year experience with excimer laser surgery for primary keratoconus in Russia. J Refract Surg 2003;19(2 suppl):S250-S254.

-12 Koller T, Iseli HP, Donitzky C, Ing D, Papadopoulos N, Seiler T: Topography-guided surface ablation for forme fruste keratoconus. Ophthalmology 2006;113:2198-2202.

13 Kim H, Choi JS, Joo CK: Corneal ectasia after PRK: clinicopathologic case report. Cornea 2006;25:845-848.

14 Piñero DP, Alio JL: Intracorneal ring segments in ectatic corneal disease - a review. Clin Experiment Ophthalmol 2010;38:154-167. 


\section{Case Reports in Ophthalmology}

\begin{tabular}{l|l}
\hline \multicolumn{2}{l}{ Case Rep Ophthalmol 2015;6:260-268 } \\
\hline DOI: 10.1159/000431306 & $\begin{array}{l}\text { ○ 2015 S. Karger AG, Basel } \\
\text { www.karger.com/cop }\end{array}$ \\
\hline
\end{tabular}

Tambe et al.: Photorefractive Keratectomy in Keratoconus

Table 1. Pre- and postoperative parameters in individual patient

\begin{tabular}{|c|c|c|c|c|c|c|c|c|c|c|c|c|c|}
\hline & \multirow{2}{*}{$\begin{array}{l}\text { Gender, } \\
\text { age, } \\
\text { years }\end{array}$} & \multicolumn{4}{|c|}{ Preoperative data } & \multicolumn{4}{|c|}{ Postoperative data (3 months) } & \multicolumn{4}{|c|}{ Postoperative data (median 7 years) } \\
\hline & & $\begin{array}{l}\text { CDVA, } \\
\text { decimal }\end{array}$ & $\begin{array}{l}\text { Refraction, } \\
\text { dpt }\end{array}$ & $\begin{array}{l}\text { Kmax, } \\
\text { dpt }\end{array}$ & $\begin{array}{l}\text { CCT, } \\
\mu \mathrm{m}\end{array}$ & $\begin{array}{l}\text { CDVA, } \\
\text { decimal }\end{array}$ & Refraction, dpt & $\begin{array}{l}\text { Kmax, } \\
\text { dpt }\end{array}$ & $\begin{array}{l}\text { CCT, } \\
\mu \mathrm{m}\end{array}$ & $\begin{array}{l}\text { CDVA, } \\
\text { decimal }\end{array}$ & Refraction, dpt & $\begin{array}{l}\text { Kmax, } \\
\text { dpt }\end{array}$ & $\begin{array}{l}\text { CCT, } \\
\mu \mathrm{m}\end{array}$ \\
\hline 1 & M, 51 & 0.2 & $-3.00-3.00 \times 100$ & 53.1 & 470 & 0.32 & $-1.00-5.00 \times 100$ & 53.1 & 480 & 0.32 & $0.50-3.75 \times 90$ & 49.7 & 373 \\
\hline 2 & $\mathrm{M}, 60$ & 0.4 & $-5.0-4.5 \times 80$ & 57.89 & 410 & 0.5 & $-3.0 \times 80$ & No data & No data & 0.5 & $+1.25-2.75 \times 69$ & 48.2 & 344 \\
\hline \multirow[t]{2}{*}{$\overline{3}$} & F, 30 & $0.32(\mathrm{LE})$ & $-6.75-3.75 \times 165$ & 49.85 & 440 & 0.8 & $-1.5-3.0 \times 30$ & 47.73 & 390 & $\begin{array}{l}\text { ALK after } 7 \\
\text { months }\end{array}$ & & & \\
\hline & & $0.4(\mathrm{RE})$ & $-1.5-0.75 \times 25$ & 45.73 & 460 & 0.8 & $-3.0 \times 60$ & 46.68 & 400 & 0.8 & $-3.0-3.0 \times 67$ & 47.73 & 500 \\
\hline 4 & M, 51 & $0.63(\mathrm{LE})$ & $\begin{array}{l}-7.0-6.5 \times 170 \\
-2.5-7.5 \times 5\end{array}$ & 52.81 & 490 & $\begin{array}{l}0.63 \\
\text { Retr. }\end{array}$ & $-3.5-2.0 \times 166$ & 47.87 & 378 & 0.8 & $-1.0-2.0 \times 163$ & 47.9 & 401 \\
\hline$\overline{5}$ & $\mathrm{M}, 50$ & 0.32 & $-9.5-1.75 \times 135$ & 55.87 & 460 & 0.4 & $-0.5-2.5 \times 125$ & 51.36 & 440 & 0.5 & $-1.5 \mathrm{cyl} \times 170$ & 51.21 & 337 \\
\hline \multirow[t]{2}{*}{$\overline{6}$} & F, 36 & $0.5(\mathrm{RE})$ & $-3.75-7.25 \times 20$ & 50.82 & 470 & 0.8 & -2.5 & 49.92 & 420 & 0.8 & $-1.0-0.5 \times 75$ & 46.48 & 433 \\
\hline & & 0.32 (LE) & $-6.5-4.5 \times 170$ & 52.00 & 470 & $0.5 \mathrm{sc}$ & No data & No data & No data & 0.8 & $-1.0-0.5 \times 77$ & 47.48 & 421 \\
\hline$\overline{7}$ & M, 36 & 0.3 & $-2.0-3.0 \times 0$ & 51.92 & 580 & - & - & No data & - & 0.4 hard CL & - & No data & 520 \\
\hline 8 & M, 47 & 0.3 & $-5.0-5.0 \times 130$ & 51.52 & 510 & 0.4 & $-0.5-2.0 \times 120$ & 47.46 & 430 & Absent & & & \\
\hline$\overline{9}$ & M, 36 & 0.3 & $-10.0-4.5 \times 120$ & No data & No data & 0.5 & $-2.75-5.0 \times 100$ & 51.21 & 440 & 0.67 & $4.0-4.0 \times 60$ & 53.65 & 423 \\
\hline 10 & F, 57 & 0.1 & $-3.75-6.0 \times 66$ & 52.48 & 520 & 0.2 & -10.0 & 53.82 & 450 & $\begin{array}{l}0.05 \text { (due to } \\
\text { cataract) }\end{array}$ & $4.0-4.0 \times 60$ & 55.97 & 423 \\
\hline 11 & $\mathrm{M}, 28$ & 0.32 & $+3.5-1.75 \times 75$ & 46.29 & 450 & 0.4 & $-4.5 \times 156$ & 48.28 & 430 & 0.5 & $+3.25-2.5 \times 90$ & 56.62 & $398^{a}$ \\
\hline 12 & M, 42 & 0.8 & $-2.0-4.25 \times 80$ & 46.29 & 510 & 0.8 & $-3.75-1.92 \times 22$ & 45.54 & 480 & 1.0 & $-3.0-1.5 \times 40$ & 45.24 & 460 \\
\hline \multirow[t]{2}{*}{13} & M, 39 & 0.25 (RE) & $+3.0-3.5 \times 90$ & 45.79 & 540 & 0.8 & $+2.25-1.25 \times 115$ & 45.42 & 495 & 0.32 & $+3.0-4.0 \times 105$ & 46.38 & 414 \\
\hline & & 0.4 (LE) & $-0.5-5.5 \times 16$ & 49.12 & 530 & 0.8 & $+2.0-2.5 \times 162$ & 45.42 & 444 & 0.8 & $+1.0-3.0 \times 155$ & 47.66 & 480 \\
\hline$\overline{14}$ & $\mathrm{M}, 21$ & 0.1 & $-8.75-5.75 \times 17$ & 53.23 & 430 & 0.5 & $-6.0-5.0 \times 150$ & 50.90 & 410 & Absent & & & \\
\hline 15 & $\mathrm{M}, 24$ & 0.3 & $-4.5-8.5 \times 125$ & 54.26 & 510 & $\begin{array}{l}0.8 \\
\text { Retr. }\end{array}$ & $-6.0-4.0 \times 125$ & 50.82 & 490 & 0.8 & $-3.75-6.0 \times 105$ & 49.12 & 440 \\
\hline 16 & $F, 29$ & 0.6 & $-2.25-3.0 \times 59$ & 51.44 & 470 & 1.0 & $-3.5-2.0 \times 5$ & 47.80 & 470 & 1.0 & $-3.25-2.5 \times 27$ & 46.87 & 470 \\
\hline 17 & M, 24 & 0.3 & $-7.0-6.0 \times 59$ & 52.57 & 456 & 0.4 & $-6.25-7.0 \times 150$ & 52.98 & 408 & 0.5 & $-3.25-7.0 \times 165$ & 50.44 & 411 \\
\hline \multirow[t]{2}{*}{18} & M, 51 & 0.1 (RE) & $-1.0-1.25 \times 90$ & 48.98 & 500 & 0.6 & $-2.25-0.5 \times 160$ & 47.46 & 461 & Absent & - & - & - \\
\hline & & 0.16 (LE) & $-0.5-2.0 \times 85$ & 48.28 & 490 & 0.4 & $-0.5-5.75 \times 18$ & 47.07 & 429 & Absent & & & \\
\hline$\overline{19}$ & M, 51 & 0.32 & $-9.75-3.25 \times 90$ & 46.42 & 440 & 0.4 & $-9.25 \mathrm{sph}$ & 44.46 & 410 & $\begin{array}{l}\text { PK after } \\
10 \text { months }\end{array}$ & & & \\
\hline 20 & $\mathrm{~F}, 47$ & 0.5 & $-5-5-2.5 \times 38$ & 55.1 & 474 & 0.4 & $-2.5-2.5 \times 10$ & 54.70 & 428 & $\begin{array}{l}\text { DALK after } \\
3 \text { months }\end{array}$ & & & \\
\hline 21 & $\mathrm{~F}, 48$ & 0.4 & $-7.0-5.0 \times 145$ & 51.92 & 480 & $\begin{array}{l}0.63 \\
\text { Retr. }\end{array}$ & $+0.75-3.5 \times 100$ & 50.67 & 337 & 0.1 & $-0.25-5.0 \times 120$ & 68.5 & $283^{\mathrm{b}}$ \\
\hline 22 & M, 36 & 0.8 & $-3.0 \times 110$ & 44.29 & 422 & 0.8 & $-3.25 \times 130$ & 45.18 & 383 & 0.8 & $+1.25-2.5 \times 115$ & 44.76 & 380 \\
\hline 23 & $\mathrm{~F}, 30$ & 0.2 & $-1.0-4.0 \times 130$ & 50.22 & 470 & 0.2 & $-2.0-5.0 \times 90$ & 46.48 & 440 & $\begin{array}{l}\text { PK after } 11 \\
\text { months }\end{array}$ & & & \\
\hline
\end{tabular}

a Planned ICRS. ${ }^{\mathrm{b}}$ Planned PK progression and planned PK. LE = Left eye; RE = right eye; Retr. = retreated; sph = sphere; ALK = anterior lamellar keratoplasty; DALK= deep anterior lamellar keratoplasty; $\mathrm{CL}$ = contact lens; $\mathrm{PK}=$ penetrating keratoplasty.

Table 2. Changes in visual acuity and refraction

\begin{tabular}{lccc}
\hline & Preoperative & 3-month follow-up & Late follow-up \\
\hline CDVA, logMAR & $0.49 \pm 0.27$ & $0.27 \pm 0.18$ & $0.24 \pm 0.28$ \\
SE refraction, dpt & $6.2 \pm 3.7$ & $3.7 \pm 3.1$ & $2.1 \pm 2.8$ \\
Refractive cylinder, dpt & $-4.2 \pm 1.9$ & $-3.0 \pm 1.8$ & $-3.0 \pm 1.7$ \\
\hline
\end{tabular}


Tambe et al.: Photorefractive Keratectomy in Keratoconus

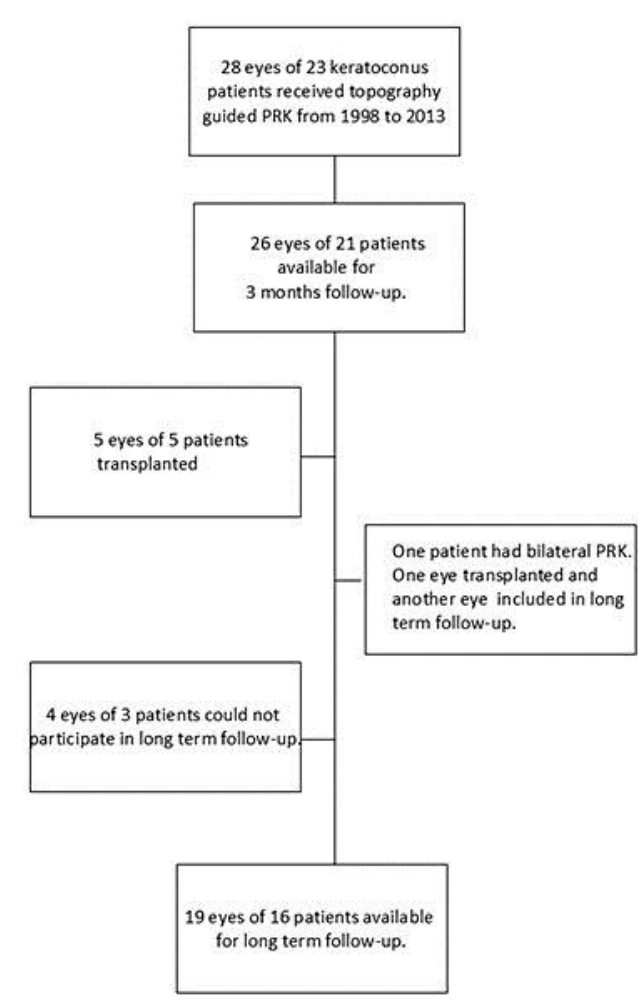

Fig. 1. Flow diagram showing the total number of keratoconus patients treated with PRK and the number of patients available for the 3-month and long-term follow-up.
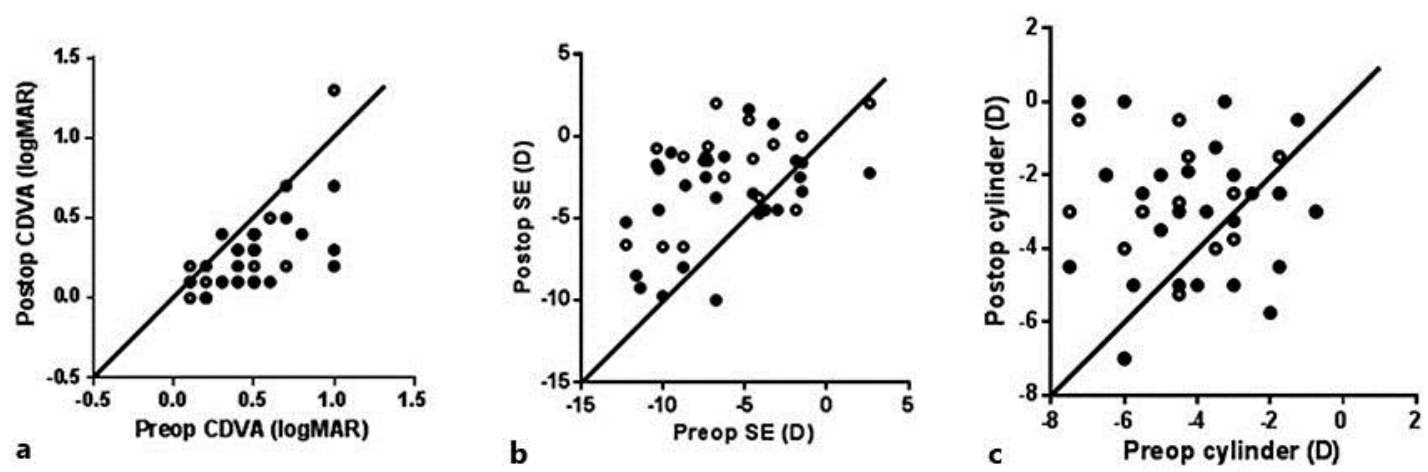

Fig. 2. a CDVA (logMAR) before as well as 3 months and several years (long-term) after topographyguided PRK for keratoconus. b Preoperative and postoperative SE refraction (D). $\mathbf{c}$ Preoperative and postoperative cylinder (D). Open circles = 3-month follow-up; closed circles = long-term follow-up. 
Tambe et al.: Photorefractive Keratectomy in Keratoconus
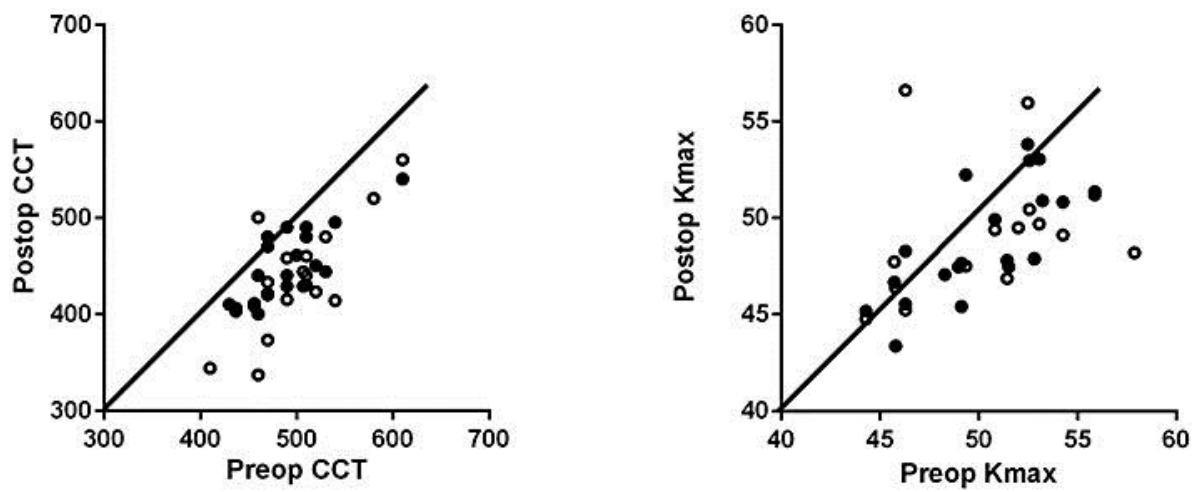

Fig. 3. a CCT $(\mu \mathrm{m})$ before as well as 3 months and several years (long-term) after topography-guided PRK for keratoconus. $\mathbf{b}$ Preoperative and postoperative Kmax (D) over the follow-up period. Closed circles = 3month follow-up; open circles = long-term follow-up. 